\title{
Don Juan de Palafox y Mendoza, promotor del libre acceso a la información en el siglo XVII novo- hispano
}

\author{
Rosa María Fernández de Zamora *
}

Artículo recibido:

7 de abril de 2011.

Artículo aceptado:

29 de julio de 2011.

\section{RESUMEN}

Don Juan de Palafox y Mendoza, arzobispo y virrey de la Nueva España y obispo de Puebla en el siglo XVII, ha sido motivo de numerosos estudios, pero lo que se desea resaltar en este escrito es su labor como fundador de la primera biblioteca pública de México y del continente americano, misma que hoy conocemos como Biblioteca Palafoxiana, y como promotor del libre acceso a la información.En el siglo XVIII, el obispo de Puebla, Francisco Fabián y Fuero, seguidor de las ideas de Palafox, enriqueció y embelleció la biblioteca y continuó con el espíritu de apertura propuesto por el fundador. También se menciona el reconocimiento que el ilustre jesuita Clavijero hizo de las obras de Palafox.

* Centro Universitario de Investigaciones Bibliotecológicas de la UNAM, México. rmfe@servidor.unam.mx

INVESTIGACIÓN BIBLIOTECOLÓGICA, Vol. 25, Núm. 54, mayo/agosto, 2011, México, ISSN: 0187-358X. pp. 141-157 
Palabras clave: Palafox y Mendoza, Juan de, 16601659; Fabián y Fuero, Francisco de, 1719-1801; Clavijero, Francisco Javier, 1731-1787; Bibliotecas públicas-México- Historia

\begin{abstract}
Don Juan de Palafox y Mendoza promoter of free access to information in the eighteenth century in New Spain

Rosa María Fernández de Zamora

Don Juan de Palafox y Mendoza, Viceroy and Archbishop of New Spain, and Bishop of Puebla in the XVII century, has been studied by many specialists. However, the purpose of this paper is to highlight his role as founder of the first public library in Mexico and in the American Continent and promoter of free acces to information. In the XVIII Century Francisco Fabián y Fuero, Bishop of Puebla, enriched and embellished the Palafoxiana library and continued the policies of its founder. Attention is also drawn to the recognition that the renowned Jesuit Clavijero made of the work of Palafox.
\end{abstract}

Keywords: Palafox y Mendoza, Juan de, 16601659; Fabián y Fuero, Francisco de, 1719-1801; Clavijero, Francisco Javier, 1731-1787; Bibliotecas públicas-México- Historia

\title{
INTRODUCCIÓN
}

$\mathrm{P}$ ara ubicarlo en el mundo de las bibliotecas recordemos que Juan de Palafox y Mendoza -nacido en Fitero, Navarra el 24 de junio de 1600- perteneció a una familia acomodada de la aristocracia española, el marquesado de Ariza, que estudió derecho en la Universidad de Salamanca y que ya como sacerdote viajó por varios países de Europa acompañando a la princesa María, hermana del rey Felipe IV, antes de venir a México. Llegó a Puebla a los 40 años, ya en edad madura. Murió en Burgo de Osma el 1 de octubre de 1659 . 


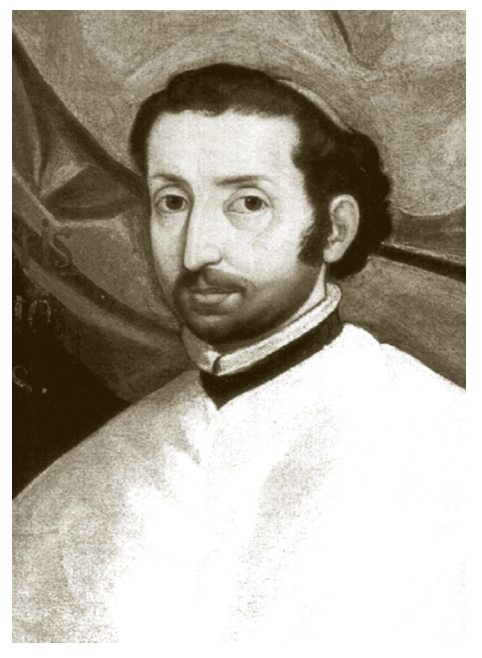

Juan de Palafox y Mendoza

Don Juan sin duda estuvo al tanto del desarrollo de las bibliotecas de su época puesto que estuvo relacionado con la corte, uno de los espacios en que las bibliotecas eran muy importantes.

El siglo XVII fue un siglo de grandes cambios, por un lado de crisis económicas y sociales y por otro de momentos gloriosos para las literaturas nacionales como fue el Siglo de Oro español con Cervantes, Lope de Vega, Calderón de la Barca y Quevedo; en Inglaterra floreció William Shakespeare y en Francia sobresalían Molière, Racine y Corneille. (Escolar Sobrino, 271).

\section{LAS BIBLIOTECAS EN EL SIGLO XVII:}

En este siglo también hay grandes cambios en el medio bibliotecario: aparecieron las primeras bibliotecas públicas, como la Bodleiana de Oxford, la del cardenal Borromeo en Milán y la de los agustinos en Roma " oú l'on puisse entrer librement \& sans difficulté...”, (Naudé p. 153), y se enriquecieron y modernizaron las bibliotecas universitarias. Las bibliotecas cambiaron sus instalaciones al imponerse el estilo de la biblioteca de El Escorial que introdujo en España la estantería adosada a las paredes en vez de colocarlas perpendicularmente. Los libros ya no estaban encadenados, a las estanterías se les colocaba tela metálica para evitar robos y los libros se agrupaban de acuerdo con el tema que trataban. 


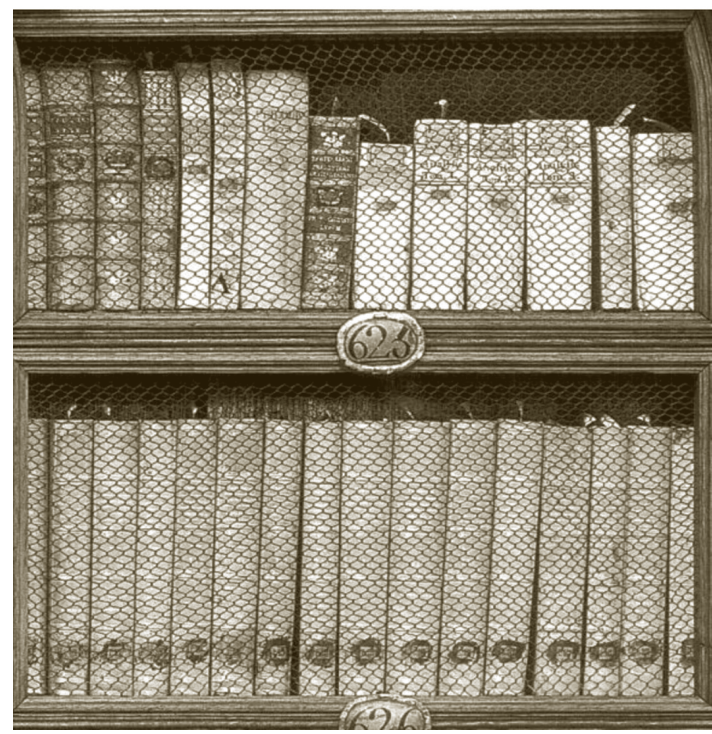

Las bibliotecas eran adornadas con globos terráqueos, relojes, astrolabios y otros objetos novedosos. Además se recomendaba la contratación de un buen bibliotecario que clasificara los libros y formara los catálogos.

Un gran promotor de la apertura de las bibliotecas a un público más amplio fue Gabriel Naudé (1600-1653), celebre bibliotecario de los cardenales Richelieu y Mazarino, primeros ministros de Francia, y posteriormente de la reina Cristina de Suecia. Naudé publicó en 1627 su famoso tratado sobre organización de bibliotecas, Advis pour dresser une bibliothèque, que se convirtió probablemente en lectura obligatoria para los bibliotecarios. Naudé decía que después de tomarse tantos trabajos y gastos en la formación de una biblioteca

no deben esconderse todas estas luces y condenar a tantos brillantes espíritus a un perpetuo silencio y soledad, eso sería no comprender el objetivo de una Biblioteca...que debe consagrarse al uso público, y no debe negarse jamás la comunicación al más sencillo de los hombres que pudiera requerirla..., (Naudé, p. 151). 


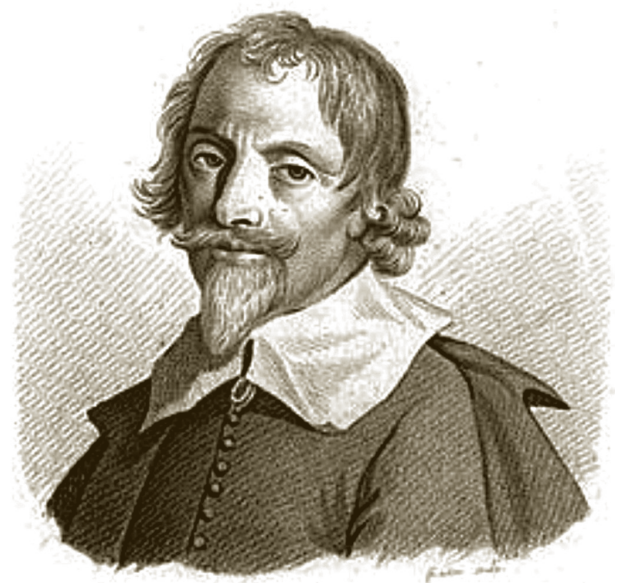

Gabriel Naudé
A D V I S

POVR DRESSER VNE BIBLIOTHEQVE

Prefenté à Monfeigneur le Prefident

de M E S ME.

Pat G. NAVDE'P.

Seconde Edition remeuë corriggé on angmentie.

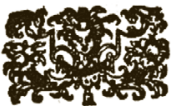

A PARIS?

Chez ROIET IE DVC, rü

S. Iacques, prés la.Pofte.

M. D C. XLIV́. iswec prisitege du Roy.

Esta idea "moderna" de biblioteca pública, es decir de compartir con otras personas la riqueza de conocimientos que contenían los libros, se extendió por Europa y sin duda Juan de Palafox la conoció, la vivió y la trajo a Puebla.

\section{Don Juan de Palafox y la donación de su biblioteca}

Palafox y Mendoza preocupado por la educación del clero, fundó en 1644 el Seminario de San Pedro, San Pablo y San Juan Evangelista en la ciudad de Puebla. A este seminario Palafox le donó su librería por escritura ante un escribano público, el 5 de septiembre de 1646, en que dispuso:

A nombre de Dios todopoderoso amen=sea notorio a todos los que el presente instrumento público vieren como nos Don Juan de Palafox y Mendoza, por la divina y apostólica gracia, obispo de este obispado de la Puebla de los Angeles... resolvimos a honra y gloria de Dios nuestro señor ser muy útil y conveniente hubiese en esta ciudad y Reino una biblioteca pública de diversas facultades y ciencias y en particular los eclesiásticos seculares y regulares y otros profesores de las letras, cursantes y pasantes, pueden estudiar como les convenga por la gran falta que suele haber de libros en estas partes, por traerse de otras tan remotas y no haber en ellas número de impresiones y comodidad de papel... hemos adquirido y juntado una librería de diversos autores, ciencias y facultades de la sagrada teología, sacros cánones, 
leyes, filosofía, medicina y buenas letras que consta de cinco mil cuerpos, poco mas o menos, que al presente tenemos en sus estantes con su rejería de alambre y otras curiosidades a ella destinadas... Por tanto... otorgamos, hacemos gracia y donación buena, pura, mera, perfecta, irrevocable por firme contrato entre vivos a los dichos tres colegios de San Pedro, San Pablo y San Juan Evangelista y para los efectos referidos de la dicha librería de cinco mil cuerpos... y de todos los demás que de aquí adelante le fuéremos agregando e incorporando con sus estantes y su rejería de alambre. Dos globos (celeste y terrestre) de a vara y media de alto; una piedra imán armada, un espejo de quemar de acero, una caja aforrada de terciopelo negro de Castilla, llena de instrumentos matemáticos y compases con dos pantómetras y una esfera pequeña adentro y dos astrolabios de pesar el sol, una balestilla para mirar la estrella... los mapas y cartas de marcar y demás instrumentos y pinturas fijas que, a nuestra elección, pusiéramos en la dicha librería... ha de estar... en la sala que así está hecha y acabada en el dicho colegio de San Pedro... patente para sus colegiales y todas las demás personas eclesiásticas y seculares de esta ciudad y su obispado que en ella quisieren quieran estudiar y ejercitar las letras a las horas acomodadas, desde las ocho a las once de la mañana y desde las tres a las cinco de la tarde, y copiar los dichos libros los que les pareciere, sin que de ninguna suerte se les pueda impedir, porque, a este efecto principalmente dirigimos esta donación... (Palafox, pp. 41-47).
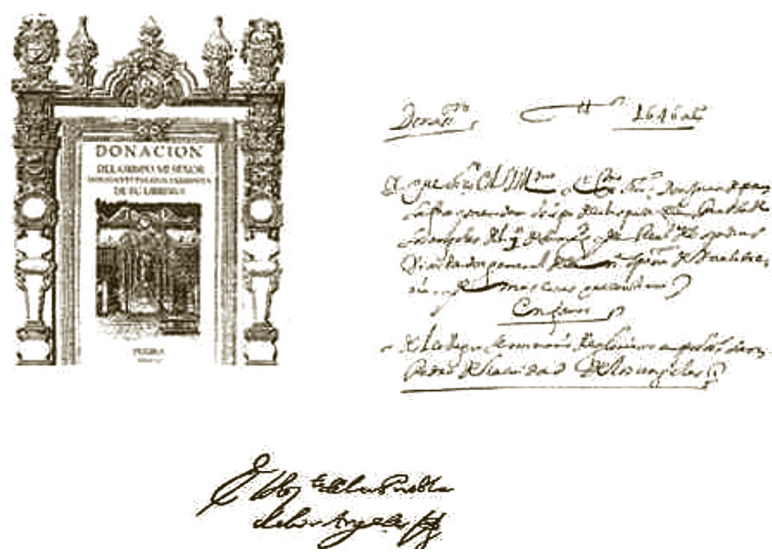

Como se puede apreciar la corriente renovadora de las bibliotecas europeas está presente en el legado de Palafox. En el texto destaca su voluntad de abrir la biblioteca a toda persona que lo requiera, con lo que establece la primera biblioteca pública en México ${ }^{1}$ y en América. Cien años después Fabián pública a la Biblioteca Turriana, fundada en 1756 a un costado de la catedral de México 
y Fuero al redactar el Reglamento de la biblioteca, acentúa esa importante característica.

Además Palafox resalta en su testamento:

y copiar los dichos libros los que les pareciere, sin que de ninguna suerte se le pueda impedir, porque a este efecto principalmente dirigimos esta donación.

Con esta disposición don Juan de Palafox instituye por primera vez en México y en América el libre acceso a la información, sin ningún impedimento, disposición revolucionaria e igualitaria en esos tiempos, y que en este siglo XXI se ha convertido en un paradigma de tanta presencia e importancia en la sociedad de la información.

Si consideramos el tiempo en que instituyó estas libertades, con ese desprendimiento, Juan de Palafox nos demuestra que fue un hombre de ideas avanzadas, un hombre moderno cuyo pensamiento coincidía plenamente con el de los intelectuales europeos como Gabriel Naudé. Recordemos que es contemporáneo de Galileo y de Descartes.

En esa época el préstamo externo no era concebible, por este motivo solicitó al Papa Inocencio X una disposición, semejante a la que protegía a la biblioteca de la Universidad de Salamanca, para proteger de robos y destrucción el acervo de la biblioteca poblana.

El breve del 7 de febrero de 1648, prohibía bajo pena de excomunión mayor que los libros fueran sacados del recinto. 


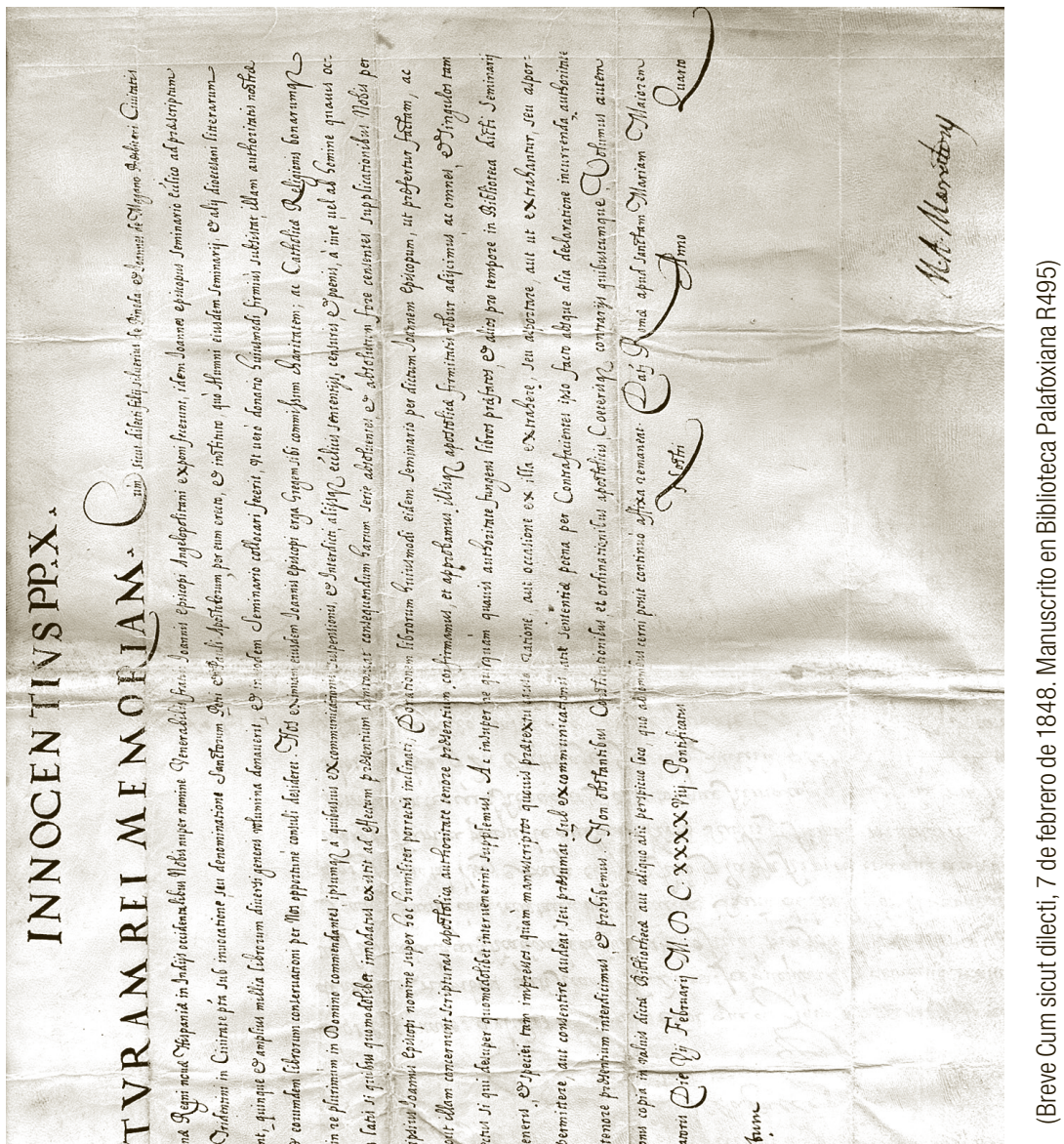


La bula que por vez primera se traduce al español dice así:

El Papa Inocencio X:

Para la futura memoria del evento: Tal como los queridos hermanos Silverio de Pineda y Juan Magano, Presbíteros de la ciudad o de la diócesis angelopolitana del reino de la Nueva España en las Indias Occidentales, hicieron de nuestro conocimiento que el mismo Obispo Juan [de Palafox], recientemente nombrado "Venerable Fray Juan”, Obispo de Puebla, donó más de cinco mil volúmenes de libros de diversos géneros al Seminario Eclesiástico, erigido e instituido por él mismo bajo el nombre o denominación de los Apóstoles San Pedro y San Pablo, según la ordenanza de los decretos del Santo Concilio de Trento en dicha ciudad, para facilitar a los alumnos del mismo Seminario y otros diocesanos el estudio de las letras; y así para que esta donación [de libros] verdaderamente permanezca más estable de ese modo [Juan de Palafox] demanda que ésta sea reforzada con la protección de nuestra autoridad y cuidada oportunamente por nosotros con la conservación de los mismos libros. Nosotros confiando muchísimo en estos asuntos en el Señor la caridad y el celo de las buenas letras y de la religión católica a la eximia congregación del mismo Juan Obispo reunida por él, absolviéndolo de cualquier excomunión, suspensión o entredicho, y de cualesquiera sentencias, censuras y penas eclesiásticas a iure o ab bomine*, contraídas en cualquier ocasión o por cualquier causa, si de algún modo ha cometido alguna, sólo para los efectos de esta presente, y juzgándolo absuelto, persuadidos por las súplicas llegadas en este tema de manera humilde a través de los hechos expuestos del mismo Obispo Juan, confirmamos y aprobamos, por la autoridad apostólica y de acuerdo con el tenor de esta presente, la donación de los libros al mismo seminario hecha por del mencionado Obispo Juan y los escritos que le acompañan de arriba, como le conciernen, de tal manera que sea presentada, y los añadimos con la fuerza de la firmeza apostólica, y suplimos a todos y cada uno de ellos tanto del derecho como del defecto cometido, si de algún modo éstos han perturbado. Y además, con dicha autoridad de acuerdo con el tenor de este comunicado, prohibimos y vedamos a cualquiera extraer o quitar, con cualquier autoridad, los libros mencionados, colocados en la Biblioteca de dicho Seminario, y otros de cualquier género y tema, tanto impresos como manuscritos bajo ningún pretexto, causa razón o motivo de ésta, o que se asuma u oiga por cualquier motivo permitir o consentir que se saquen o quiten, bajo pena de excomunión ipso facto para los desobedientes sin algún pretexto válido. No obstante las disposiciones expuestas y las regulaciones apostólicas, queremos que la copia de las presentes prohibiciones, permanezca siempre pegada en las puertas de dicha biblioteca o en algún otro lugar visible donde pueda ser distinguida por todos y por cualquiera del resto de los contrarios. Dada en Roma en la casa de Santa María Mayor, bajo el año Piscatoris, el día 7 de febrero de 1648. (Traducción de Guillermo Saúl Morales Romero). 
En este interesante texto podemos advertir que se aprecian los cinco mil volúmenes que el "Venerable fray Juan", obispo de Puebla dona al seminario porque facilitará y apoyará los estudios de las letras, religiosas se entiende, y considerando que don Juan está libre de falta alguna y que de tenerla queda absuelto de ella, confirman y aprueban dicha donación y más adelante cumplen con la solicitud del obispo al mencionar:

...con dicha autoridad...prohibimos y vedamos a cualquiera extraer o quitar, con cualquier autoridad los libros mencionados, colocados en la Biblioteca de dicho Seminario, y otros de cualquier género y tema, tanto impresos como manuscritos bajo ningún pretexto, causa razón o motivo de ésta, o que se asuma u oiga por cualquier motivo permitir o consentir que se saquen o quiten, bajo pena de excomunión ipso facto para los desobedientes sin algún pretexto válido...

Seguramente esta disposición permaneció pegada en las puertas de la biblioteca por mucho tiempo. El Reglamento para el uso de la biblioteca, dictado por Fabián y Fuero en 1763, en el inciso 17, señala "Siempre estará en público, y de modo que todos la puedan leer la Bula, en que con pena grave de excomunión mayor está prohibido el sacar libro alguno, o papel de esta librería”, (Osorio, p. 52).

\section{Don Juan de Palafox y los Jesuitas}

Es sabido que entre los jesuitas y el obispo Palafox y Mendoza existió una tensión constante. Hasta la fundación del seminario, los jesuitas con sus cinco colegios dominaban la educación de la sociedad poblana. De éstos, unos estaban destinados a la formación de nuevos miembros de la Compañía otros a la educación de los jóvenes poblanos y otros a la de los indígenas. Probablemente esta rivalidad redundó en beneficio de ambas instituciones, porque en ello iba también el prestigio de los miembros del clero regular -los jesuitas-y el del secular para los cuales Palafox fundó el seminario.

Sin embargo pese a esas desavenencias, años después, el ilustre jesuita Francisco Xavier Clavigero escribió un poema dedicado a don Juan de Palafox. Pedro Angel Palou menciona que la importancia del texto de Clavigero está en el reconocimiento y su cálido elogio:

califica su vida de portentosa, en la vida y en sus obras, lo llama gran hombre... vivió y no murió, ganó la inmortalidad y dejó enorme herencia en la memoria humana..., (Palou. Clavigero p. 6, 9). 
El poema traducido al español empieza así:

Es difícil decir cual fue mayor portento

Si la vida que el llevó

O las obras que realizó

Entre las obras realizadas por el obispo, una de las más notables es la biblioteca Palafoxiana.

\section{Francisco Fabián y Fuero, y la biblioteca palafoxiana.}

La biblioteca se fue enriqueciendo con las donaciones hechas por los sucesores de Palafox como Manuel Fernández de Santa Cruz y de manera muy sobresaliente por el interés y el entusiasmo de don Francisco Fabián y Fuero, nombrado obispo de Puebla por Carlos III en 1765.

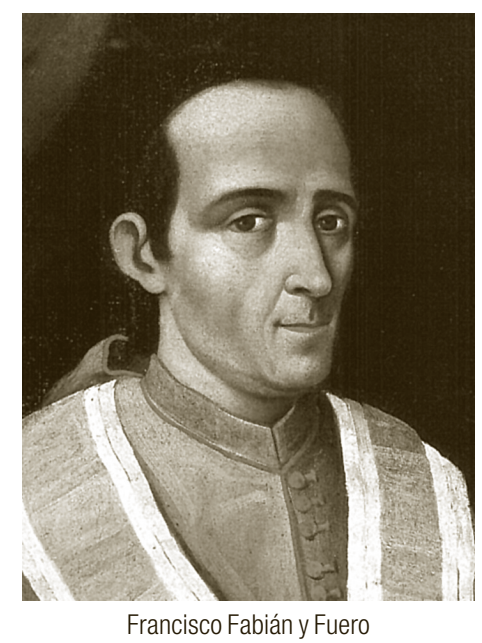

Fabián y Fuero no sólo donó también su biblioteca en 1771, sino que logró que una buena parte de las bibliotecas de los jesuitas fueran destinadas a la biblioteca del Seminario lo que propició que la sala que ocupaba fuera insuficiente por lo que le mandó construir una estantería de madera de cedro con capacidad para 20,000 volúmenes, tal como la admiramos hoy en día, siguiendo el modelo de las bibliotecas universitarias de ese tiempo. Los biógrafos de Fabián y Fuero dicen que estudió en las universidades de Alcalá 
y Valladolid, no dicen que hubiese estado o estudiado en Salamanca, pero el parecido de la Palafoxiana con la biblioteca histórica de la Universidad de Salamanca con su estantería construida por Alberto Churriguera en 1749, es notable.

En la introducción al Reglamento que Fabián y Fuero redactó en 1773 con motivo de su inauguración asienta:

...hemos juzgado de la mayor necesidad e importancia, el ampliar en los mismos nuestros colegios la pieza que estaba destinada a la librería, hasta ponerla en los términos de extensión y hermosa arquitectura en que hoy se ve con admiración y placer de todos, y aumentar, como lo hemos dicho, sus libros en no pocos y bien selectos volúmenes.

Hemos seguido en esto el espíritu de su incomparable fundador don Juan de Palafox y Mendoza, cuyo infatigable celo no contento con sacar de cimientos y completar la obra de los expresados seminarios, les dio la prueba más expresiva de su amor en la donación que les hizo en utilizar del público de toda su librería, que siempre ba merecido y tenido justamente el renombre de biblioteca pública, y queriendo no solo la conservación, sino también en cuanto sea posible el aumento en lo material y formal de esta obra tan importante y suntuosa, hemos resuelto poner la última mano con el establecimiento de las siguientes reglas y ordenanzas, bajo las cuales mandamos se gobierne inviolablemente esta biblioteca de nuestros seminarios a beneficio de estos y del público, (Osorio p. 48).

Palou señala que Clavigero en su "descripción de la ciudad de los Angeles", escrita ya en el exilio, muestra un gran conocimiento sobre aquella Puebla barroca del siglo XVIII, en la que vivió de adolescente y durante sus visitas a los colegios jesuitas. La que recuerda como una ciudad muy importante y hermosa. Al mencionar los colegios y seminarios Clavigero se refiere a la biblioteca que conocemos como Palafoxiana al señalar

Entre los colegios y seminarios, el que más sobresale por su construcción es el de San Pedro y San Pablo... Hay en él una biblioteca que tanto por la artística estantería de maderas preciosas cuanto por el número de volúmenes, puede muy bien compararse a las más célebres de Europa sobre todo después del despojo de las librerías de los jesuitas (Palou, Clavigero p. 29)

Fabián y Fuero reorganizó la biblioteca a tal punto que puede considerarse, con toda justicia, que su labor revitalizó la biblioteca, lo que permitió que llegara hasta nuestros días. Sin embargo él siempre quiso anteponer la figura de Palafox a la suya, como reconocimiento a la labor fundadora de su antecesor. 


\section{LA BIBLIOTECA PALAFOXIANA}

Poco se sabe desde cuando se le denomina Palafoxiana. ¿Quién le dio ese nombre? En los documentos coloniales, se refieren a ella como la Biblioteca del Seminario. Melchor Ocampo, en 1836, ya la menciona como Biblioteca Palafoxiana.

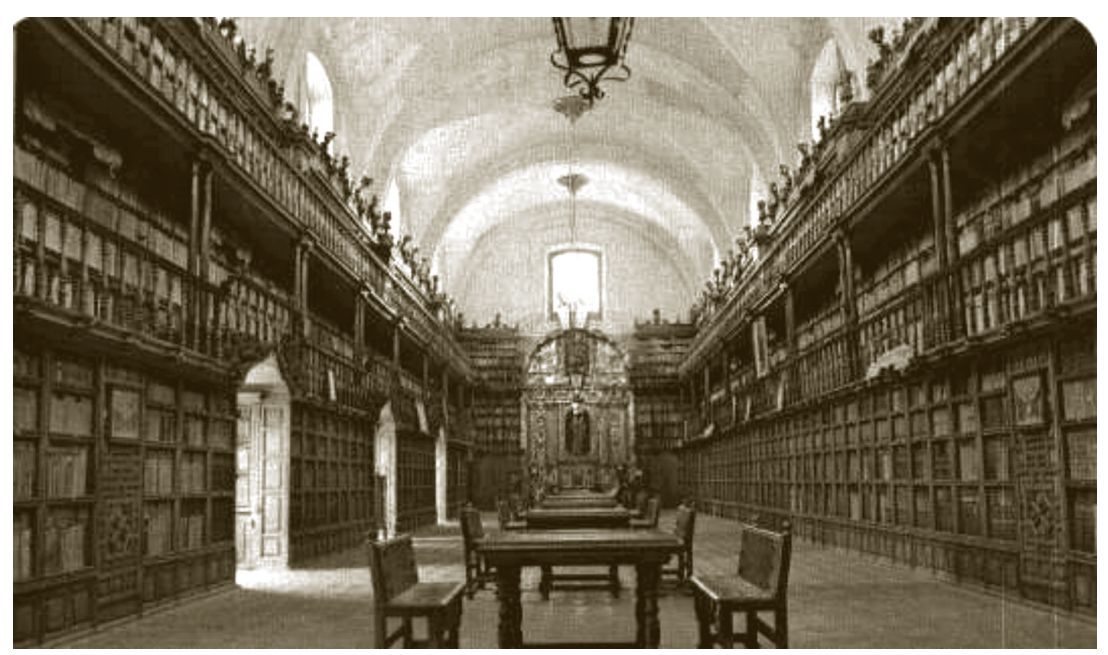

Biblioteca Palafoxiana

La fama de la Palafoxiana se extendió por todo el territorio y en el siglo XIX ya era obligada la visita a la biblioteca como lo atestiguan las guías de forasteros y las crónicas de personajes como Melchor Ocampo e Ignacio Manuel Altamirano, quienes dejaron valiosos testimonios sobre su estado y sus colecciones. Melchor Ocampo dice que la biblioteca tenía en 1836, 12,536 volúmenes y señala las lenguas en que estabann escritos. Altamirano en sus observaciones expresa que

La mayor parte de las obras son de teología, cánones e historia eclesiástica; hay... dos ejemplares de las obras de Humboldt y Bonpland, otros dos magníficos del Quijote... un ejemplar de la famosa gramática egipcia de Champollion, una colección curiosísima y de un tamaño extraordinario de cartas geográficas antiguas..., (Osorio, p. 95).

En 1913 don Juan B. Iguínez, ilustre bibliógrafo y bibliotecario de la primera mitad del siglo XX, visitó la biblioteca y escribió una reseña en la que expresa 
Hablar de los tesoros bibliográficos que allí se guardan, sería una tarea demasiado prolija... Pueden verse preciosas biblias de los siglos XVII y XVIII, magníficos atlas de la misma época, notables por sus grabados en cobre por famosos artistas, los mejores tratados de patrología, ciencias sagradas... historia antigua y moderna, no siendo escasas las ediciones princeps con sus vetustas pero hermosas pastas de piel o pergamino... una obra de valor inestimable, que es considerada como una de las más raras de la biblioteca... la Crónica de Nüremberg, editada en esa ciudad por Antonio Koberger en 1493, (Iguínez p. 8).

El atlas con grabados de cobre, al que se refire Iguíniz, es el de Orteluis, Amberes, 1584. La Biblia políglota o Biblia regia, fue impresa por Cristóbal Plantino, en Amberes.

A su vez, Pedro Angel Palou informa que la Palafoxiana tiene un impreso mexicano de Pedro Balli, 1575, la Doctrina Cristiana de Juan de la Anunciación.

En el siglo XVII surgen los catálogos o bibliografías que

delimitaban o alababan un patrimonio literario 'nacional' cuya excelencia fue presentada a la Europa letrada como un contrapunto intelectual a la decadencia política y militar de la monarquía católica, (Chartier p. 26).

Se publicaron el Epitome de una Bibliotbeca oriental i occidental, náutica y geográfica de Antonio León Pinelo y la Bibliotheca Hispana Nova e Hispana Vetus de Nicolas Antonio. Estos textos respondían a las inquietudes de la pérdida de esas colecciones y también el temor a la abundancia de publicaciones. Estas obras se encontraban en el acervo de la Palafoxiana.

Como podemos observar Palafox y Fabian y Fuero, son personajes que representan la modernidad de su época, que incorporaron esa modernidad a la biblioteca del seminario al considerar que el conocimiento debería estar al alcance del público sin restricción alguna para consultar y usar la información. Sin embargo, en el siglo XX la biblioteca no vivió la modernidad pues por mucho tiempo fue convertida en un museo, contraviniendo los deseos de sus famosos fundadores y sobreponiendo la conservación sobre el libre acceso y uso del acervo de la biblioteca.

La Biblioteca Palafoxiana, que ahora debe considerarse una biblioteca especializada, una biblioteca para la investigación, afortunadamente en este siglo XXI ha recobrado la modernidad que le otorgaron sus ilustres varones fundadores; es ahora una biblioteca viva tal como lo exige la UNESCO a través de su Programa Memoria del Mundo. Después de los daños sufridos por el sismo de 1999, la biblioteca fue restaurada mediante el programa Biblioteca 
Palafoxiana del Tercer Milenio. En 2005 la UNESCO la reconoció como patrimonio cultural de la humanidad, al inscribirla en el Registro Memoria del Mundo. Cuenta con un catálogo automatizado disponible en disco compacto titulado Pasión, ciencias y sentires. Biblioteca Palafoxiana; los investigadores pueden utilizar el acervo, y numerosas exposiciones y cursos se organizan para difundir sus riquezas.

En Europa las bibliotecas con fondos antiguos están reviviendo en este mundo globalizado, como signos de identidad; los países las dan a conocer usando las nuevas tecnologías de la información, digitalizando sus colecciones y beneficiando a innumerables estudiosos del mundo entero.

\section{Conclusiones}

Como conclusión se puede afirmar que si don Juan de Palafox y Mendoza y don Francisco Fabian y Fuero vivieran en estos tiempos hubiesen sido los primeros en utilizar la computadora, en tener la página Web de la biblioteca en Internet, en usar el Facebook y el twitter, es decir hubiesen aprovechado todos los avances de las tecnologías de la información para promover y dar a conocer los tesoros documentales que guarda su muy ilustre Biblioteca Palafoxiana, que es un signo de identidad de la cultura poblana y mexicana.

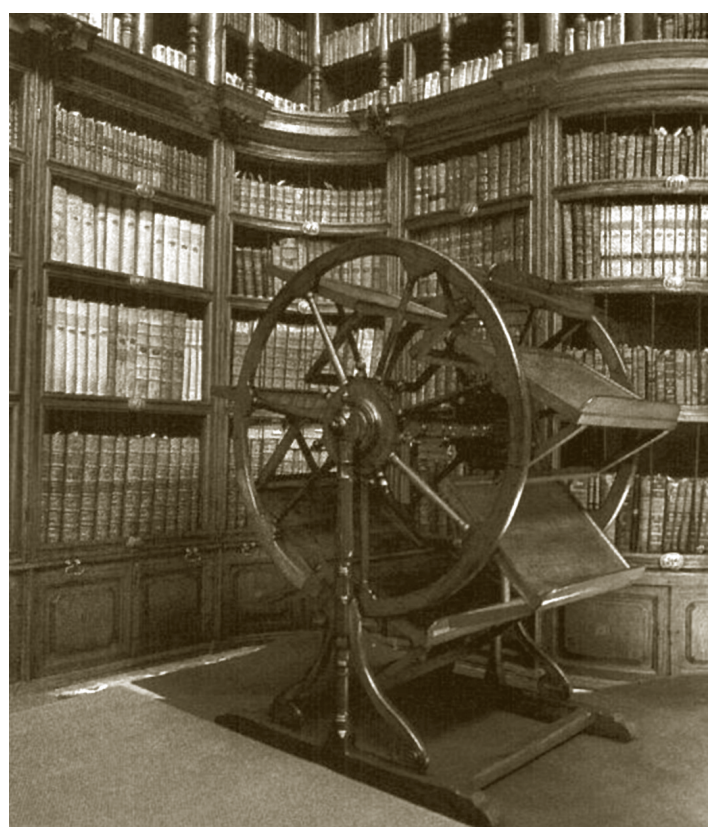




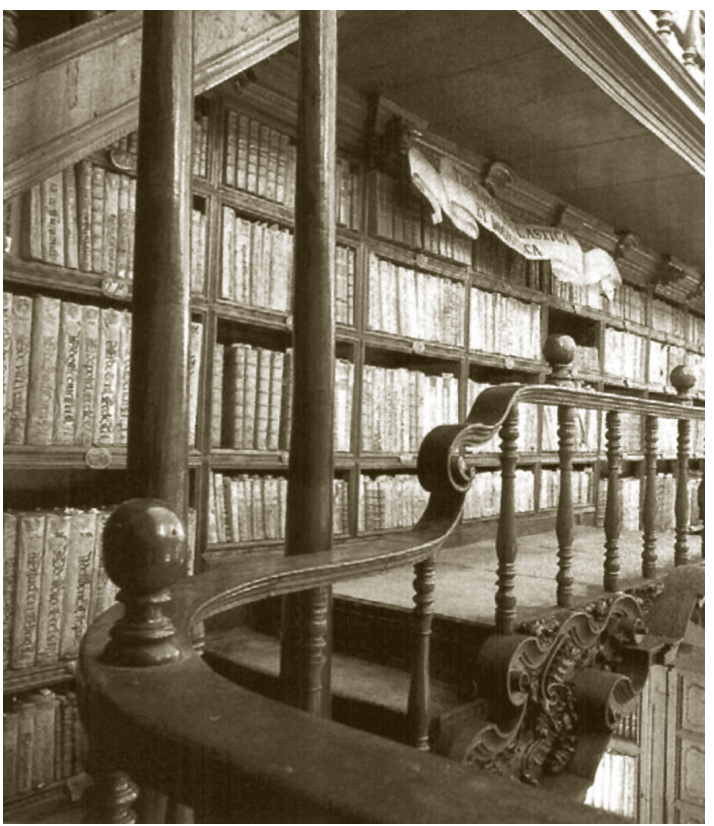

\section{OBRas CONSULTADAS}

Beristáin de Souza, José Mariano, Biblioteca Hispanoamericana septentrional, México: UNAM, 1980, 2 v.

Biblioteca Palafoxiana, Artes de México, Revista libro, 68. 2003

Caillet, Maurice, Les bibliothècaires. Histoire des bibliothèques francaises, París: Promodis-Cercle de la Librairie, 1986-88, V.2

Chartier, Roger, "De Alejandría a Angelópolis. Bibliotecas de piedra y bibliotecas de papel”, en Biblioteca Palafoxiana. Artes de México, 2003, pp. 23-29

Escolar Sobrino, Hipólito, Historia de las bibliotecas, Madrid: Fundación Germán Sánchez Ruipérez, 1987.

Fernández Gracia, Ricardo, Palafox y su pasión por los libros. Biblioteca Palafoxiana. Artes de México, 2003, pp. 39-43.

Iguíniz, Juan B., La Biblioteca Palafoxiana de Puebla, El Lábaro, 1913, pp. 3-8.

Ocampo, Melchor, Biblioteca Palafoxiana, El Ateneo, Oct. 1836, pp. 416-417.

Montiel, Alejandro, El rescate de la Biblioteca Palafoxiana, Biblioteca Palafoxiana. Artes de México, 2003, pp. 53-57.

Osorio Romero, Ignacio, Historia de las bibliotecas en Puebla, México: SEP, Dirección General de Bibliotecas, 1988. 
Palafox y Mendoza, Juan de, Donación del obispo mi señor don Juan de Palafox y Mendoza de su librería, Puebla, 1646, Puebla: Secretaría de Cultura, 1998, (Colección Documentalia, VIII).

Palou, Pedro Ángel, Clavigero y Palafox. Con un inédito del bistoriador mexicano sobre el obispo, Puebla en Clavigero y Clavigero en Puebla, Puebla: Secretaría de Cultura, 1998, (Colección Documentalia, X).

Palou, Pedro Angel, Breve noticia histórica de la Biblioteca Palafoxiana y de su fundador Juan de Palafox y Mendoza; y los colegios de San Juan, San Pedro, San Pablo y San Pantaleón, 4 ed. Puebla: Secretaría de Cultura, 1995. (Lecturas históricas de Puebla. Nueva época, 110).

, Breve noticia de la biblioteca Palafoxiana. Biblioteca Palafoxiana. Artes de México, 2003, pp. 50-52

Pasión, ciencias y sentires, Biblioteca Palafoxiana. Catálogo, Puebla: Secretaría de Cultura/Apoyo al desarrollo de Archivos y Bibliotecas de México, A.C., 2010, Disco compacto.

Torre Villar, Ernesto, Nuevas aportaciones a la Biblioteca Palafoxiana, 1950.

Ciudad Universitaria, 27 de junio, 2011 